\title{
Cerebral microdialysis of interleukin (IL)-13 and IL-6: extraction efficiency and production in the acute phase after severe traumatic brain injury in rats
}

\author{
Hedy Folkersma • John J. P. Brevé • Fred J. H. Tilders • \\ Leela Cherian • Claudia S. Robertson • \\ W. Peter Vandertop
}

Received: 14 August 2007 / Accepted: 1 March 2008/Published online: 25 November 2008

(C) The Author(s) 2008. This article is published with open access at Springerlink.com

\begin{abstract}
Background As a research tool, cerebral microdialysis might be a useful technique in monitoring the release of cytokines into the extracellular fluid (ECF) following traumatic brain injury (TBI). We established extraction efficiency of Interleukin(IL)-1ß and Interleukin(IL)- 6 by an in vitro microdialysis-perfusion system, followed by in vivo determination of the temporal profile of extracellular fluid cytokines after severe TBI in rats.
\end{abstract}

H. Folkersma $\cdot$ W. P. Vandertop

Neurosurgical Center Amsterdam, VU University Medical Center, Amsterdam, The Netherlands

H. Folkersma

e-mail: hedy.folkersma@vumc.nl

J. J. P. Brevé • F. J. H. Tilders

Department of Medical Pharmacology,

VU University Medical Center,

P.O. Box 7057, NL-1008 MB Amsterdam, The Netherlands

J. J. P. Brevé

e-mail: jjp.breve@vumc.nl

F. J. H. Tilders

e-mail: fjh.tilders@vumc.nl

L. Cherian $\cdot$ C. S. Robertson

Department of Neurosurgery, Baylor College of Medicine,

Scurlock Tower, Suite 944, 6560 Fannin Street,

Houston, TX 77030-2731, USA

C. S. Robertson

e-mail: claudiar@bcm.tmc.edu

H. Folkersma $\cdot$ W. P. Vandertop $(\square)$

Department of Neurosurgery, VU University Medical Center,

P.O. Box 7057, NL-1008 MB Amsterdam, The Netherlands

e-mail: wp.vandertop@vumc.nl
Materials and methods In vitro experiments using a polyether sulfon (PES) microdialysis probe especially developed for recovery of macromolecules such as cytokines, were carried out to establish the extraction efficiency of IL-1ß and IL-6 from artificial cerebrospinal fluid (CSF) with defined IL-1ß and IL-6 concentrations. In vivo experiments in which rats were subjected to TBI or sham and microdialysis samples were collected from the parietal lobe for measurement of cytokines.

Findings The extraction efficiency was maximal $6.05 \%$ (range, 5.97-6.13\%) at $0.5 \mu \mathrm{l} / \mathrm{min}^{-1}$ and decreased at higher flow rates. Both cytokines were detectable in the dialysates. Highest IL-1ß levels were found within $200 \mathrm{~min}$, highest IL- 6 concentrations were detected at later intervals (200-400 $\mathrm{min}$ ). No differences were found between the TBI and control groups.

Conclusions Cerebral microdialysis allows measurement of cytokine secretion in the ECF of brain tissue in rats.

Keywords Brain injury · Cytokines · ELISA · Interleukins · IL-1 beta $\cdot$ IL- $6 \cdot$ Microdialysis

$\begin{array}{ll}\text { Abbreviations } \\ \text { BSA } & \text { bovine serum albumine } \\ \text { CCI } & \text { controlled cortical impact } \\ \text { aCSF } & \text { artificial cerebrospinal fluid } \\ \text { ECF } & \text { extracellular fluid } \\ \text { IL } & \text { interleukin } \\ \text { MD } & \text { microdialysis } \\ \text { PES } & \text { polyether sulfon } \\ \text { SD } & \text { Sprague-Dawley } \\ \text { TBI } & \text { traumatic brain injury } \\ \text { TNF } & \text { tumour necrosis factor }\end{array}$




\section{Introduction}

Traumatic brain injury (TBI) results in an inflammatory cascade, initiated by the release of inflammatory cytokines $[3,8,9,13,16,17,28,41-43]$. The exact contribution of these substances to local tissue damage is still not fully understood.

IL-1ß exhibits several actions in the brain, critical for host defence against brain injury and disease. This pluripotent, pro-inflammatory cytokine participates in a complex network of signalling molecules and seems to be one of the most important factors in the propagation and maintenance of the inflammatory cascade after TBI, being responsible for enhancing the activation of T-cells $[3,8,20$, 27]. IL-1 $\beta$ belongs to the IL- 1 family which has three wellknown endogenous ligands, two agonists, IL- $1 \alpha$ and IL-1 $\beta$, and one IL-1 receptor antagonist [23]. IL-1 $\beta$ is synthesised as a cytosolic precursor protein of $31 \mathrm{kDa}$ and after cleavage in the mature $17 \mathrm{kDa}$ form, it becomes biologically active [18, 32, 45]. Microglia, expressing caspase-1, the enzyme responsible for cleaving pro-IL-1 $\beta$, has been recognised to be the earliest and major source of IL-1. Also, various other endogenous brain cells, such as astrocytes, oligodendroglia, neurones, endothelial cells, and circulating immune cells, are able to express IL-1 $\beta[4,38]$. At least two types of IL-1 receptors are known, type I (IL1RI) transduces the IL-1 signal and is widely expressed, type II (IL-1RII) is found on B cells, neutrophils and monocytes and preferentially binds IL- 1 B. IL-1 $B$ mediates the release of multiple pro-inflammatory cytokines, chemokines, prostaglandins, and other inflammatory mediators $[4,14]$.

The pleotropic cytokine IL-6 mediates both deleterious and beneficial effects following TBI [44] and acts in synergy with IL-1 and tumour necrosis factor alpha (TNF$\alpha$ ), augmenting the response of immune cells to other cytokines [40]. It has a molecular weight of $26 \mathrm{kDa}$ and belongs to a superfamily of structurally related cytokines with diverse biological properties. IL-6 is released in response to IL-1 and TNF- $\alpha$, and secreted by T cells, astrocytes, microglia, and neurones [15]. The IL-6 receptor, present on the cell surface, consists of an IL-6 binding alpha chain and a signal transducer, gp130, which is shared among the receptors for the IL-6 related cytokine subfamily. Interactions of IL-6 with its receptor give rise to profound inflammatory cytokine production [46].

Intracerebral microdialysis is based on the principle of diffusion of water-soluble substances across a semipermeable membrane, and clinical experience is rapidly increasing in patients with an ischaemic stroke, vasospasm-induced ischaemia after subarachnoid haemorrhage and severe brain trauma [49]. In the extracellular fluid (ECF), liquid found between the cells containing proteins and electrolytes, profound disturbances have been demonstrated in concen- trations of glutamate and aspartate and energy-related metabolites such as lactate, pyruvate, adenosine, inosine and hypoxanthine after brain injury and these changes correlate with the severity of the injury [2, 6, 29, 31, 33-35].

Recovery of cytokines and neurotrophins from the ECF of the brain has been reported in patients suffering from severe TBI using cerebral microdialysis $[50,51]$. Although these observations are promising, we wondered whether intracerebral implantation of the microdialysis probe alone would affect cytokine production in the brain. Using a cerebral microdialysis probe, we first studied IL- $1 ß$ and IL6 extraction efficiency in vitro followed by subsequent in vivo studies to determine the temporal profile of IL- $1 ß$ and IL-6 release in the extracellular fluid after TBI.

\section{Materials and methods}

Throughout this paper we use the term "extraction efficiency" to describe the cytokine concentration in the dialysate expressed as a fraction of the cytokine concentration in the sample medium [7].

\section{Microdialysis in vitro}

We used a $2 \mathrm{~mm}$ length microdialysis PES probe (CMA/12 14/02 PES CMA/Microdialysis AB Solna, Sweden) with an outer diameter of $0.5 \mathrm{~mm}$ and a molecular weight cut-off of $100 \mathrm{kDa}$ especially developed for microdialysis experiments on high molecular weight substances equipped with a micro-injection pump and microfraction collector (CMA/ 102 CMA/142 CMA/Microdialysis AB Solna, Sweden). The inlet $(12 \mathrm{~cm})$ and outlet $(7 \mathrm{~cm})$ tubings from the microdialysis probe were connected to a syringe cannula and microfraction collector, respectively. The microdialysis perfusion fluid and the sample medium $(2.5 \mathrm{ml})$ consisted of artificial CSF (Na $147 \mathrm{mmol} \mathrm{L}^{-1}$; $4 \mathrm{mmol} \mathrm{L}^{-1}$; Ca $2.3 \mathrm{mmol} \mathrm{L}^{-1}$; $\mathrm{Cl} 156 \mathrm{mmol} \mathrm{L}^{-1}$; $\mathrm{pH}$ 6.0; $290 \mathrm{mOsm} \mathrm{L}^{-1}$ ) containing $0.5 \mathrm{mg} / \mathrm{ml}^{-1}$ bovine serum albumin (BSA) fraction V (BSA; Sigma-Aldrich Chemie Steinheim, Germany) unless otherwise stated.

\section{Sampling procedures}

For measurements of the extraction efficiency, the microdialysis probe was placed in an Eppendorf tube, sealed hermetically containing $2.5 \mathrm{ml}$ of sampling medium with one of four different concentrations $\left(2,10,50,250 \mathrm{ng} \mathrm{ml}^{-1}\right)$ of recombinant rat IL-1ß or recombinant rat IL-6 (gift from Dr S Poole, NIBSC, Potters Bar, UK). The standard cytokine solutions were prepared freshly preceding each in vitro experiment. Sequential dialysate samples of $100 \mu \mathrm{l}$ each were collected in airtight Eppendorf tubes containing 
$150 \mu \mathrm{l}$ High Performance ELISA (HPE)-buffer solution (Central Laboratory of the Netherlands Red Cross Blood Transfusion Service, Amsterdam, The Netherlands), and stored at $-20^{\circ} \mathrm{C}$ until assayed for rat IL- $1 \beta$ and rat IL- 6 . All conditions were tested in at least two parallel experiments. To maintain a constant environmental temperature, all in vitro experiments were performed at $37.0^{\circ} \mathrm{C}$ in a desiccation stove.

In one set of experiments, the microdialysis probe remained in the sampling medium (cytokine concentration: $\left.50 \mathrm{ng} \mathrm{ml}^{-1}\right)$, and the flow rate was increased stepwise (0.5$2.0 \mu \mathrm{l} / \mathrm{min}^{-1}$ ) to establish the effect of flow rate on extraction efficiency. In another set of experiments, we studied the relationship between the cytokine concentrations outside the probe with that in the dialysate. Therefore, the flow rate was kept constant $\left(1.0 \mu \mathrm{l} / \mathrm{min}^{-1}\right)$ and the dialysis probe was transferred at $200 \mathrm{~min}$ intervals into sampling medium containing increasing concentrations of cytokines $\left(2,10,50\right.$, and $\left.250 \mathrm{ng} \mathrm{ml}^{-1}\right)$. In this experiment, sample interval was $100 \mathrm{~min}$.

To study the temporal relationship between changes in cytokine concentration outside the probe versus the dialysate, the probe was placed in medium containing 10 or $50 \mathrm{ng} / \mathrm{ml}^{-1}$ IL-1ß or IL-6 for $600 \mathrm{~min}$. Flow rate was maintained at $1.0 \mu \mathrm{l} / \mathrm{min}^{-1}$ and six dialysate samples were collected. Thereafter, the probe was transferred into cytokine free sample medium for another $200 \mathrm{~min}$, and two sequential samples of $100 \mathrm{~min}$ were collected.

\section{Surgical preparation and controlled cortical impact (CCI)}

The tail artery was cannulated with a $14 \mathrm{G}$ polymer catheter (length $25 \mathrm{~mm}$ ) and connected to a pressure transducer to monitor blood pressure and obtain blood gases. The head of the animal was mounted in a stereotactic frame. After a midline scalp incision, a craniotomy was performed over the right hemisphere extending from the lambda to the bregma and zygomatic arch. In six rats, a standard severe CCI was applied as described by Dixon et al. [10]. The impactor tip with a diameter of $7 \mathrm{~mm}$ was adjusted to produce an impact at the centre of the exposed brain with an impact velocity of $5 \mathrm{~m} / \mathrm{s}^{-1}$, duration of $130 \mathrm{~ms}$, and a depth of $3 \mathrm{~mm}$. The impact velocity of the CCI was monitored with the use of a computer software program (LabView for Windows). Sham rats underwent an identical surgical procedures but did not undergo a CCI. The microdialysis probe was placed stereotactically in the right hemisphere at a depth of $3 \mathrm{~mm}$ (co-ordinates: $-1.5 \mathrm{~mm}$ bregma, $3.0 \mathrm{~mm}$ lateral), afterwards. After CCI or sham procedure, via a small burrhole, an intracranial pressure monitor and brain temperature device was placed in the contralateral frontal hemisphere. Subsequently, the scalp incision was closed. Animals remained in the stereotactic frame throughout the whole experiment.
Microdialysis in vivo

Twelve adult, male SD rats (300-350 g; Harlan, Indianapolis, USA) were accustomed to the laboratory for at least $24 \mathrm{~h}$. They were anaesthetised with Isoflurane $5 \%$ in a ventilated anaesthesia chamber. After endotracheal intubation with a 16-gauge Teflon catheter, the rats were mechanically ventilated at a respiratory rate of 80 breaths per minute and remained under full anaesthesia during the whole experiment (Isoflurane $2 \%$ in oxygen $45 \%$ ). The animals were evaluated every $15 \mathrm{~min}$ for level of anaesthesia by monitoring the pinch reflex. Rats were either subjected to focal TBI $(n=6)$ or served as controls $(n=6)$. Directly thereafter, the microdialysis probe was inserted to a depth of $3 \mathrm{~mm}$ into the penumbra zone of the lesion or normal brain parenchyma (controls) according to the following coordinates: $-1.5 \mathrm{~mm}$ from bregma, $3.0 \mathrm{~mm}$ lateral from midsagittal line and perfusion was started at a flow rate of $1.0 \mu \mathrm{l} / \mathrm{min}^{-1}$. Similar to the in vitro experiments, the microdialysis perfusion fluid consisted of artificial CSF containing $0.5 \mathrm{mg} \mathrm{ml}^{-1}$ BSA fraction $\mathrm{V}$. The sampling procedure was started $30 \mathrm{~min}$ after probe insertion. Four sequential dialysate samples were collected, at a time interval of $100 \mathrm{~min}$. Animals remained in the stereotactic frame throughout the experiment. Body and brain temperatures where kept within normal range. At the end of the experiment, the rats were sacrificed by decapitation.

Cytokine assays

IL- $1 \beta$ and IL- 6 concentrations of the medium and dialysates were measured using an enzyme-linked immunosorbent assay (ELISA) specific for rat IL-1 $\beta$ and rat IL-6 as described elsewhere in detail $[25,37,39]$. The detection limit of the assay was $10 \mathrm{pg} \mathrm{IL-} 1 \beta \mathrm{ml}^{-1}$ and $50 \mathrm{pg} \mathrm{IL}-6 \mathrm{ml}^{-1}$, respectively.

\section{Statistical analysis}

Data is expressed as mean \pm standard deviation. Pearson correlation coefficients were used to analyse the correlation between the measured cytokine concentration of the medium and cytokine concentration of the dialysates obtained. Differences were rated significant at a probability error of less than 0.05 . The statistical evaluation was carried out using SPSS 9.0 for Windows.

Animal ethics

The research protocol for the in vivo experiments as outlined above was reviewed and approved by the Animal Protocol Review Committee at Baylor College of Medicine Houston, Texas USA, using the National Institutes of 
Health guidelines for the care and use of laboratory animals.

\section{Results}

Microdialysis in vitro

In vitro microdialysis experiments using dialysis fluid without serum albumin, revealed low but detectable concentrations of IL-1ß $\left(6 \mathrm{pg} / \mathrm{ml}^{-1}\right)$ only in the first dialysate sample $(50 \mathrm{~min})$. In all subsequent dialysate samples, including the wash-out samples, IL-1ß concentrations were below the lower limit of detection. Measurements of IL-1ß in the medium itself, showed a substantial decrease in IL-1ß concentration (from 3,277 to $305 \mathrm{pg} / \mathrm{ml}^{-1}$ ) before and after dialysis for $200 \mathrm{~min}$. Also, a gradual decrease in concentrations of IL- 6 in the dialysates was found. Extraction efficiency decreased from $7.07 \%$ at the beginning of the experiment to $2.24 \%$ at $200 \mathrm{~min}$. In both wash out samples, IL-6 concentrations were below detection limit $\left(<40 \mathrm{pg} / \mathrm{ml}^{-1}\right)$. Samples taken from the medium at 0 and $200 \mathrm{~min}$, showed a more than $50 \%$ decrease in cytokine concentration. As the disappearance of IL- $1 \beta$ and IL-6 from the medium may relate to non-specific binding to tubing, MD probe, vials etcetera, we added a protein coat to the medium and perfusion fluid $\left(0.5 \mathrm{mg} / \mathrm{ml}^{-1}\right.$ BSA). This resulted in steady concentrations of cytokines in the medium. Furthermore, extraction efficiency at a certain flow rate was found constant during the experiment. Therefore, BSA was used in all experiments described.

Experiments in which the flow rate was altered during perfusion revealed that increased flow rates resulted in decreasing extraction efficiencies $(r=-0.746, p<0.05)$. For instance, at a flow rate of $0.5 \mu 1 / \mathrm{min}^{-1}$, the mean extraction efficiency was $6.05 \%$ (range: 5.97-6.13) and increasing the flow rate to $1.0 \mu 1 / \mathrm{min}^{-1}$ decreased the mean extraction efficiency of IL-1ß to $1.46 \%$ (range $0.73-2.89$ ).

Experiments designed to study the relationship between the cytokine concentration outside the probe with that in the dialysate revealed a linear relationship $(r=0.953, p<0.05$, two tailed) between the cytokine concentration in the medium and microdialysis samples over a wide concentration range. In these experiments that are carried out at a flow rate of $\mathrm{ml} \mathrm{min}^{-1}$, the extraction efficiencies of IL-1ß and IL-6 were $0.82 \pm 0.60 \%$ and $0.75 \pm 0.49 \%$, respectively (Fig. 1).

\section{Microdialysis in vivo}

In three CCI and four control rats, detectable IL-1 $\beta$ $\left(>1.2 \mathrm{pg} / \mathrm{ml}^{-1}\right)$ was found in one or more dialysate samples. Except for one control rat, in all of these "IL-1ß responders", the highest levels IL-1ß were found in the

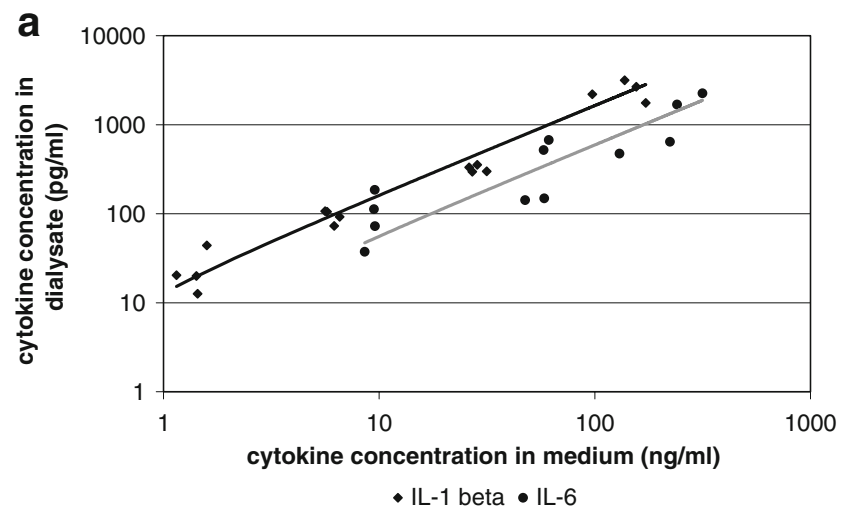

b

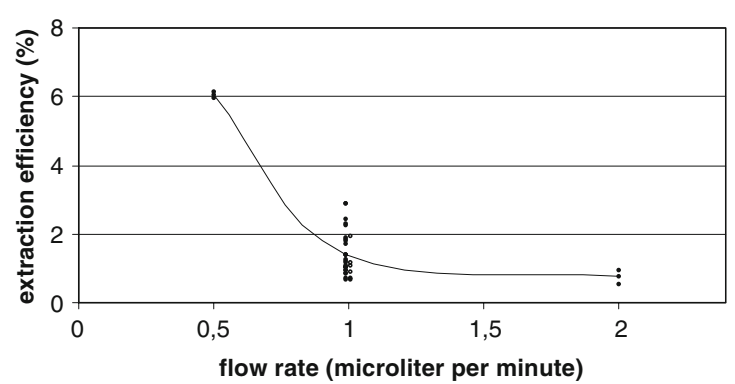

Fig. 1 a Relationship between cytokine concentration in the medium and in the dialysate sample. Studies were performed at a flow rate of $1 \mathrm{ml} \mathrm{min}{ }^{-1}$. Stepwise increase in cytokine concentrations in medium result in proportional changes in the dialysate. b Relationship between extraction efficiency and flow rate as determined in vitro

first 100 min following insertion of the microdialysis probe (mean: $9.0 \pm 9.2 \mathrm{pg} / \mathrm{ml}^{-1}$ ). In one control rat, the highest ECF IL- $\beta$ concentration was found at 200 min. Concentrations of IL-1ß were lowest at $300 \mathrm{~min}$ following insertion of the microdialysis probe (mean: $3.7 \pm 2.2 \mathrm{pg} / \mathrm{ml}^{-1}$ ). Mean IL-1ß concentrations at 200 and 400 min was $6.4 \pm 6.2$ and $4.9 \pm 2.6 \mathrm{pg} / \mathrm{ml}^{-1}$, respectively. No significant differences in IL-1 $1 \beta$ concentrations were found between $\mathrm{CCI}$ and control rats (Fig. 2a).

Four CCI and five control rats had detectable IL-6 concentrations $\left(>20 \mathrm{pg} / \mathrm{ml}^{-1}\right)$ in one or more dialysate samples. Except for one CCI rat, all "IL-6 responders" had the highest IL- 6 concentrations $\left(43.8 \pm 16.6 \mathrm{pg} / \mathrm{ml}^{-1}\right)$ at the end of the experiment (400 min). One CCI rat had the highest ECF IL-6 concentrations at $300 \mathrm{~min}$. Furthermore, a gradual increase in IL-6 concentrations was noted. At $100 \mathrm{~min}$, IL-6 was detectable in only one sample $\left(25.6 \mathrm{pg} / \mathrm{ml}^{-1}\right)$. Mean IL-6 concentrations at 200 and $300 \mathrm{~min}$ were $26.5 \pm 1.6$ and $38.3 \pm$ $26.8 \mathrm{pg} / \mathrm{ml}^{-1}$, respectively. No significant differences in expressions of IL-6 were found between CCI and sham operated rats (Fig. 2b).

Six out of seven "IL-1ß responders" were "IL-6 responders" as well $(n=6)$. Four of these belonged to the control group. In one CCI rat, only IL-1 3 was detectable in the dialysates. Three rats, of which two belonged to the 

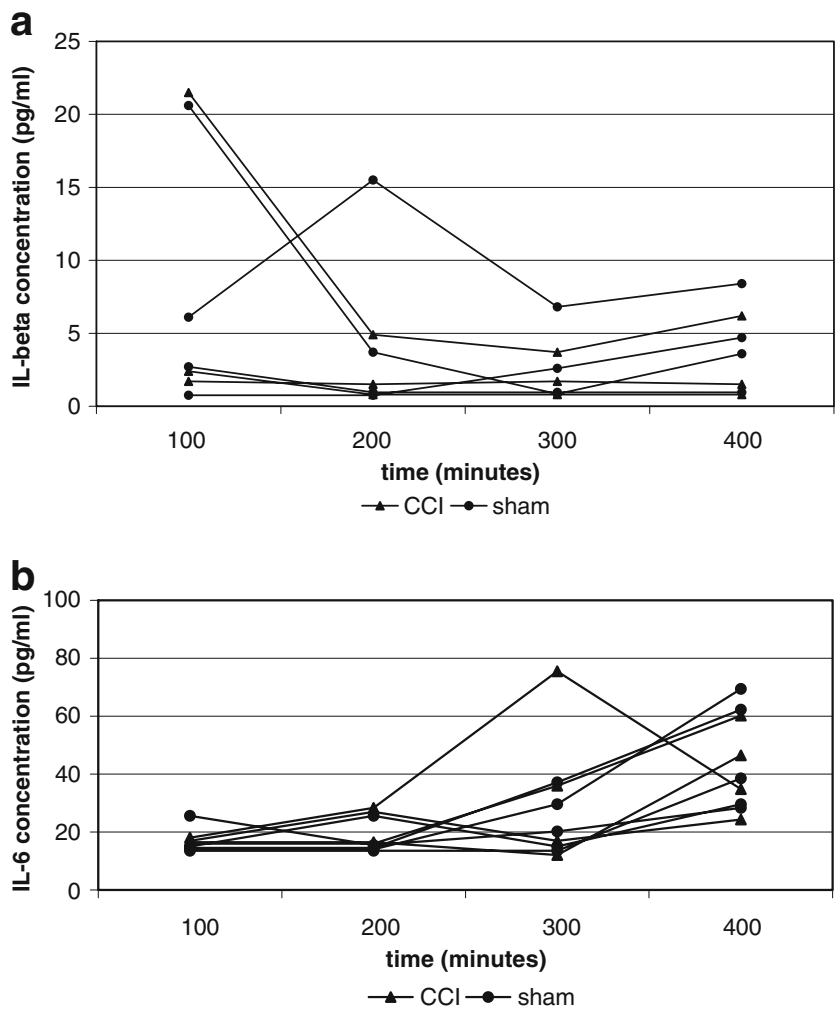

Fig. 2 a, b Temporal pattern of cytokines in the rat brain following CCI and control conditions. a Extracellular IL-1ß, b extracellular IL-6. Ordinate shows time interval following probe implantation. Connected datapoints refer to individual rats

control group, were "IL-6 responders" but IL-1ß was not detectable in any of the samples. In two rats, one CCI and one control, both IL-1ß and IL- 6 concentrations were below the detection limit.

\section{Discussion}

In the present study we demonstrated that the extraction efficiency of IL-1 $\beta$ and IL-6 is constant over a wide concentration range of these cytokines, using in vitro approaches. Using in vivo microdialysis, we show the temporal pattern of cytokine secretion in the brain of rats during the acute phase of brain surgery and CCI.

\section{Microdialysis in vitro}

In vitro studies were designed to study extraction efficiency of cytokines, in which BSA was added to the microdialysis perfusion fluid and sample medium. Serum albumins are often used to saturate non-specific binding sites on plastics and other materials, thereby reducing non-specific binding of low abundancy proteins, peptides and other materials [19]. Indeed, addition of BSA to the medium largely prevented cytokine disappearance and markedly increased the cytokine concentrations in the samples and improved the consistency of the results. At a flow rate of $1.0 \mu \mathrm{l} / \mathrm{min}^{-1}$, steady state cytokine concentrations were measured within $1.5 \mathrm{~h}$ after placement of the probe in a cytokine-containing medium. Thus, at this flow rate the present set up allows signals outside the microdialysis probe to be detected in the dialysate with a delay of approximately $1-1.5 \mathrm{~h}$.

Appropriate interpretation of the results of cytokine measurements in the microdialysis samples requires knowledge on the relationship between ECF cytokine concentration and the levels measured in the dialysate. In the present study, we demonstrate a fair linear correlation between the cytokine concentration as measured in the medium and that in the dialysates over a wide concentration range of IL-1ß and IL-6. This indicates that alterations in the signal measured in the dialysate can be interpreted as proportional changes in the medium outside the membrane i.e. in the ECF. The data further show a mean extraction efficiency of rat IL-1ß and IL6 of $1.2 \%$ and $0.7 \%$, respectively.

As expected, the extraction efficiency is affected by the flow rate. As shown in the present data, increasing the flow rate results in a non-linear decline in extraction recovery. We hypothesise that in addition to flow rate dependent sample dilution, increasing the flow rate leads to an increase in hydrostatic pressure which may result in a net outflow of dialysate fluid and consequently in a non proportional decline in the apparent diffusion of cytokine across the membrane. From this perspective, the flow rate should be as low as acceptable to increase cytokine recovery. Given the lower limit of sample volume for appropriate sample handling, reduction of the flow rate will require increased sample collection time and consequently reduce the temporal resolution of alterations in cytokine secretion. Thus, the conditions represent a compromise that is largely dictated by the extraction efficacy, the lower limit of detection of the cytokines and, temporal resolution required in the experiment.

The zero net flux method as described by Lönnroth et al. is another, well known approach to investigate recovery rates of substrates by microdialysis. Varying the concentration gradient over the microdialysis membrane by gradually increasing the substrate of interest in the perfusion fluid, a corresponding change in net influx in the dialysate can be recorded [26].

\section{Microdialysis in vivo}

Following on our in vitro experiments, we performed experiments in rats either exposed to focal brain injury or sham procedure. The goal of these experiments was twofold. First, to explore the feasibility of cytokine extraction from the ECF of the brain using cerebral 
microdialysis. Secondly, to elucidate the temporal profile of extracellular IL-1 13 and IL- 6 in the acute phase after TBI.

Both IL- $1 \beta$ and IL- 6 were detectable in the dialysates in seven and nine animals, respectively. Highest expressions of IL-1ß were found in the first samples obtained. Given the delay of the signal which is in the present setup approximately $60-90 \mathrm{~min}$, it seems that IL- $1 \beta$ that is present in the first sample is supposed to be secreted short after placement of the dialysis probe in healthy or traumatised brain tissue. This observation is in accordance with previous studies, which have shown increased expression of IL-1ß in the acute phase following traumatic brain injury $[12,21,22]$. IL- $1 \beta$ is a pluripotent cytokine and plays a key role in the inflammatory cascade [3, 48]. It has been reported that IL- $1 \beta$ acts as a mediator in the inflammatory response and induces the expression of neuroprotectant - and neurotrophic factors in a traumatised brain [30]. Furthermore, enhanced glial activation is associated with increased expression of inflammationrelated mRNA's, including IL-1 $\beta$, TNF- $\alpha$ and, IL-6 [24].

Most of the early experimental TBI studies measured high levels of cytokines in brain homogenates, which include both intracellular and extracellular proteins. Raghupathi and colleagues found increased IL-1ß levels at one hour after trauma, which remained elevated up to $6 \mathrm{~h}$ [36]. Experiments from the same group show significantly increased IL-1ß mRNA expression one till six hours after TBI [11]. Taupin et al. found increased IL-6 and IL-1 levels, $8 \mathrm{~h}$ after trauma in the ipsilateral cortex. Elevated cytokine concentrations were observed up to $18 \mathrm{~h}$ and decreased thereafter to basal values [47]. As compared to these studies, the lower cytokine concentration found in our series using cerebral microdialysis, might be due to the lower level of secreted cytokines in the ECF.

Our findings suggest that release of IL- $1 \beta$ precedes a gradual increase in expression of IL-6. Increased expression of IL-1 13 in the acute phase after brain injury could be the mediator of the increased production of IL- 6 . The proinflammatory cytokine IL-1ß, induces CNS glial cells to produce other cytokines [14]. In a study of Knoblach et al., significantly elevated IL-1ß were found 4 hours after fluid percussion brain injury in the ipsilateral cortex [22]. Moreover, Acarin et al. found increased expression of IL$1 \beta$ and TNF- $\alpha$ followed by cytokine positive cells for IL- 6 in an adjacent area 2-10 $\mathrm{h}$ after injection of N-methyl-Daspartate, producing an excitotoxic lesion in the brain [1].

In our study, no significant difference in extracellular IL$1 \beta$ and IL- 6 concentrations was found between TBI rats and controls. From extensive research work done by, amongst others, Feuerstein and co-workers, it is known that inflammatory processes endure for at least several days after brain injury [13]. In our experiments, the time of measuring cytokines $(400 \mathrm{~min})$ is probably too short to explore the whole spectrum of the post-traumatic neuroinflammatory cascade. However, one of the main purposes of this pilot study is to explore whether it is possible to measure cytokine release in rat brain with the use of microdialysis techniques. In the future, an experimental setup, in which animals are awake and monitored for a longer period, will be an interesting follow-up study.

Fairly frequently, IL-1ß and IL-6 levels were found below the lower detection limit in the dialysates. Early microdialysis experiments of Benveniste et al., tissue reactions were found adjacent to the microdialysis probe. In the first days after insertion, haemorrhage surrounding the probe was found occasionally. Late tissue effects consisted of collagen deposits and occasional granuloma formation [5]. Although the microdialysis probes used are designed for studies on high molecular weight substances, pores of the membranes could be blocked by blood or brain particles due to traumatic alterations of brain tissue, thereby reducing extraction efficiency. If this is the case, further slow down of the flow rate in the in vivo experiments will possibly increase the cytokine extraction resulting in higher cytokine concentrations in the dialysates. Taking the increased sampling time into account and adjusting sample frequency, lowering the flow rate or ultimately a stop flow experiment would be interesting in long-term microdialysis experiments.

The specific contribution of the surgical procedures, and in particular penetration of the microdialysis probe in the brain parenchyma itself, to the inflammatory response is an important factor in the interpretation of our microdialysis data. Woodroofe et al. showed in their studies that the probe itself, without additional trauma, is sufficient to elicit a local immune response in the brain with increased IL-1, 2 days after implantation. IL-6 was strongly increased early until day 1 and decreased by day 2 [52]. Although minimally invasive, the microdialysis technique could give rise to a restricted acute inflammatory response. If this is the case, the (local) inflammatory cascade could lead to haemostatic disturbances in the brain tissue surrounding the probe, resulting in changes of concentrations of substrates in the interstitial fluid and thereby influencing the microdialysis results. Therefore, using cerebral microdialysis in monitoring metabolic and neurochemical parameters as well as mediators of the inflammatory cascade in the ECF of injured brain tissue, one has to take into account that local environmental disturbances caused by the microdialysis probe itself, might result in temporary alterations in substance concentrations.

\section{Conclusions}

Microdialysis allows monitoring of IL- $1 \beta$ and IL-6 secretion into the damaged brain. Addition of a carrier protein to the medium and the perfusion fluid markedly enhances the 
apparent extraction efficiency, thereby facilitating the detection of cytokines in microdialysis studies in vivo. Extraction efficiency is consistent for at least eight hours for both cytokines tested, independent of the cytokine concentration. Extraction efficiency decreases by increasing flow rate. Extraction efficiency at higher flow rates is not reliable when using a PES membrane with a high molecular weight cut off $(100 \mathrm{kDa})$.

Our findings further suggest that release of IL-1ß precedes a gradual increase in expression of extracellular IL-6. No significant difference was found between injured and sham operated rats in expression of extracellular Il-1ß and IL- 6 indicating that surgical procedures and implantation of the microdialysis probe itself may cause cytokine release in the brain. Further studies are therefore needed to determine whether cerebral microdialysis for monitoring cytokines may be useful in this field of research.

Acknowledgements The Neurosurgery Foundation AZVU supported this study. Recombinant rat IL- $1 \beta$ and IL-6 and reagents for measurements of rat IL- 13 and IL- 6 were kindly provided by Dr. Stephan Poole (National Institute for Biological Standards and Control, Potters Bar, UK).

Open Access This article is distributed under the terms of the Creative Commons Attribution Noncommercial License which permits any noncommercial use, distribution, and reproduction in any medium, provided the original author(s) and source are credited.

\section{References}

1. Acarin L, Gonzalez B, Castellano B (2000) Neuronal, astroglial and microglial cytokine expression after an excitotoxic lesion in the immature rat brain. Eur J Neurosci 12(10):3505-3520

2. Alves OL, Bullock R, Clausen T, Reinert M, Reeves TM (2005) Concurrent monitoring of cerebral electrophysiology and metabolism after traumatic brain injury: An experimental and clinical study. J Neurotrauma 22(7):733-749

3. Arvin B, Neville LF, Barone FC, Feuerstein GZ (1996) The role of inflammation and cytokines in brain injury. Neurosci Biobehav Rev 20(3):445-452

4. Basu A, Krady JK, Levison SW (2004) Interleukin-1: A master regulator of neuroinflammation. J Neurosci Res 78(2):151-156

5. Benveniste H, Diemer NH (1987) Cellular reactions to implantation of a microdialysis tube in the rat hippocampus. Acta Neuropathol 74(3):234-238

6. Berger C, Sakowitz OW, Kiening KL, Schwab S (2005) Neurochemical monitoring of glycerol therapy in patients with ischaemic brain odema. Stroke 36(2):E4-E6

7. Cano-Cebrian MJ, Zornoza T, Polache A, Granero L (2005) Quantitative in vivo microdialysis in pharmacokinetic studies: Some reminders. Curr Drug Metabol 6(2):83-90

8. Chiaretti A, Genovese O, Aloe L, Antonelli A, Piastra M, Polidori G, Di Rocco C (2005) Interleukin 1 beta and interleukin 6 relationship with paediatric head trauma severity and outcome. Childs Nerv Syst 21(3):185-193

9. Csuka E, Morganti-Kossmann MC, Lenzlinger PM, Joller H, Trentz O, Kossmann T (1999) IL-10 levels in cerebrospinal fluid and serum of patients with severe traumatic brain injury: relationship to IL-6, TNF-alpha, TGF-beta 1 and blood-brain barrier function. J Neuroimmunol 101(2):211-221

10. Dixon CE, Clifton GL, Lighthall JW, Yaghmai AA, Hayes RL (1991) A controlled cortical impact model of traumatic brain injury in the rat. J Neurosci Methods 39(3):253-262

11. Fan L, Young PR, Barone FC, Feuerstein GZ, Smith DH, McIntosh TK (1995) Experimental brain injury induces expression of interleukin-1-beta messenger-Rna in the rat-brain. Mol Brain Res 30(1):125-130

12. Fassbender K, Schneider S, Bertsch T, Schlueter D, Fatar M, Ragoschke A, Kuhl S, Kischka U, Hennerici M (2000) Temporal profile of release of interleukin-1 beta in neurotrauma. Neurosci Lett 284(3): 135-138

13. Feuerstein GZ, Wang XK, Barone FC (1998) The role of cytokines in the neuropathology of stroke and neurotrauma. Neuroimmunomodulation 5(3-4):143-159

14. Friedman WJ (2001) Cytokines regulate expression of the type 1 interleukin-1 receptor in rat hippocampal neurones and glia. Exp Neurol 168(1):23-31

15. Godbout JP, Johnson RW (2004) Interleukin-6 in the aging brain. J Neuroimmunol 147(1-2):141-144

16. Goodman JC, Robertson CS, Grossman RG, Narayan RK (1990) Elevation of tumour-necrosis-factor in head-injury. J Neuroimmunol 30(2-3):213-217

17. Hayakata T, Shiozaki T, Tasaki O, Ikegawa H, Inoue Y, Toshiyuki F, Hosotubo H, Kieko F, Yamashita T, Tanaka H, Shimazu T, Sugimoto H (2004) Changes in CSF S100B and cytokine concentrations in early-phase severe traumatic brain injury. Shock 22(2):102-107

18. Hazuda DJ, Strickler J, Simon P, Young PR (1991) Structurefunction mapping of interleukin-1 precursors - cleavage leads to a conformational change in the mature protein. J Biol Chem 266 (11):7081-7086

19. Jensen SM, Hansen HS, Johansen T, Malmlof K (2007) In vivo and in vitro microdialysis sampling of free fatty acids. J Pharm Biomed Anal 43(5):1751-1756

20. Jones NC, Prior MJW, Burden-Teh E, Marsden CA, Morris PG, Murphy S (2005) Antagonism of the interleukin-1 receptor following traumatic brain injury in the mouse reduces the number of nitric oxide synthase-2-positive cells and improves anatomical and functional outcomes. Eur J Neurosci 22(1):72-78

21. Kamm K, VanderKolk W, Lawrence C, Jonker M, Davis AT (2006) The effect of traumatic brain injury upon the concentration and expression of interieukin- 1 beta and interleukin-10 in the rat. $J$ Trauma Inj Infect Crit Care 60(1):152-157

22. Knoblach SM, Susan MKC (2000) Cortical interleukin-1 beta elevation after traumatic brain injury in the rat: no effect of two selective antagonists on motor recovery. Neurosci Lett 289(1):5-8

23. Konsman JP, Drukarch B, Dam AM (2007) (Peri)vascular production and action of pro-inflammatory cytokines in brain pathology. Clin Sci 112(1-2):1-25

24. Kyrkanides S, O'Banion MK, Whiteley PE, Daeschner JC, Olschowka JA (2001) Enhanced glial activation and expression of specific CNS inflammation-related molecules in aged versus young rats following cortical stab injury. J Neuroimmunol 119 (2):269-277

25. Lenczowski MJP, Van Dam AM, Poole S, Larrick JW, Tilders FJH (1997) Role of circulating endotoxin and interleukin-6 in the ACTH and corticosterone response to intraperitoneal LPS. Am J Physiol Regul Integr Comp Physiol 42(6):R1870-R1877

26. Lonnroth P, Jansson PA, Smith U (1987) A microdialysis method allowing characterization of intercellular water space in humans. Am J Physiol 253(2):E228-E231

27. Lu KT, Wang YW, Yang JT, Yang YL, Chen HI (2005) Effect of interleukin-1 on traumatic brain injury - induced damage to hippocampal neurones. J Neurotrauma 22(8):885-895 
28. Lucas SM, Rothwell NJ, Gibson RM (2006) The role of inflammation in CNS injury and disease. Br J Pharmacol 147:S232-S240

29. Meixensberger J, Kunze E, Barcsay E, Vaeth A, Roosen K (2001) Clinical cerebral microdialysis: brain metabolism and brain tissue oxygenation after acute brain injury. Neurol Res 23(8):801-806

30. Miyachi T, Asai K, Tsuiki H, Mizuno H, Yamamoto N, Yokoi T, Aoyama M, Togari H, Wada Y, Miura Y, Kato T (2001) Interleukin-1 beta induces the expression of lipocortin 1 mRNA in cultured rat cortical astrocytes. Neurosci Res 40(1):53-60

31. Nilsson P, Hillered L, Ponten U, Ungerstedt U (1990) Changes in cortical extracellular levels of energy-related metabolites and amino-acids following concussive brain injury in rats. J Cereb Blood Flow Metab 10(5):631-637

32. Oprica M, Eriksson C, Schultzberg M (2003) Inflammatory mechanisms associated with brain damage induced by kainic acid with special reference to the interleukin-1 system. J Cell Mol Med 7(2):127-140

33. Peerdeman SM, Girbes ARJ, Polderman KH, Vandertop WP (2003) Changes in cerebral interstitial glycerol concentration in head-injured patients; correlation with secondary events. Intensive Care Med 29(10):1825-1828

34. Peerdeman SM, Girbes ARJ, Vandertop WP (2000) Cerebral microdialysis as a new tool for neurometabolic monitoring. Intensive Care Med 26(6):662-669

35. Peerdeman SM, Girbes ARJ, Vandertop WP (2002) Changes in cerebral glycolytic activity during transport of critically ill neurotrauma patients measured with microdialysis. J Neurol 249(6):676-679

36. Raghupathi R, McIntosh TK, Smith DH (1995) Cellular-responses to experimental brain injury. Brain Pathol 5(4):437-442

37. Rees GS, Ball C, Ward HL, Gee CK, Tarrant G, Mistry Y, Poole S, Bristow AF (1999) Rat interleukin 6: expression in recombinant Escherichia coli, purification and development of a novel ELISA. Cytokine 11(2):95-103

38. Rothwell N (2003) Interleukin-1 and neuronal injury: mechanisms, modification, and therapeutic potential. Brain Behav Immun 17(3):152-157

39. SafiehGarabedian B, Poole S, Allchorne A, Winter J, Woolf CJ (1995) Contribution of interleukin-1-beta to the inflammationinduced increase in nerve growth-factor levels and inflammatory hyperalgesia. Br J Pharmacol 115(7):1265-1275

40. Santhanam U, Ghrayeb J, Sehgal PB, May LT (1989) Posttranslational modifications of human interleukin-6. Arch Biochem Biophys 274(1):161-170

41. Shiozaki T, Hayakata T, Tasaki O, Hosotubo H, Fuijita K, Mouri T, Tajima G, Kajino K, Nakae H, Tanaka H, Shimazu T, Sugimoto H (2005) Cerebrospinal fluid concentrations of anti-inflammatory mediators in early-phase severe traumatic brain injury. Shock 23 (5):406-410

42. Shohami E, Novikov M, Bass R, Yamin A, Gallily R (1994) Closed-head injury triggers early production of Tnf-Alpha and Il-6 by brain-tissue. J Cereb Blood Flow Metab 14(4):615-619

43. Singhal A, Baker AJ, Hare GMT, Reinders FX, Schlichter LC, Moulton RJ (2002) Association between cerebrospinal fluid interleukin-6 concentrations and outcome after severe human traumatic brain injury. J Neurotrauma 19(8):929-937
44. Stover JF, Schoning B, Beyer TF, Woiciechowsky C, Unterberg AW (2000) Temporal profile of cerebrospinal fluid glutamate, interleukin-6, and tumour necrosis factor-alpha in relation to brain edema and contusion following controlled cortical impact injury in rats. Neurosci Lett 288(1):25-28

45. Stylianou E, Saklatvala J (1998) Interleukin-1. Int J Biochem Cell Biol 30(10):1075-1079

46. Taga T, Kishimoto T (1997) gp130 and the interleukin-6 family of cytokines. Annu Rev Immunol 15:797-819

47. Taupin V, Toulmond S, Serrano A, Benavides J, Zavala F (1993) Increase in Il-6, Il-1 and Tnf levels in rat-brain following traumatic lesion - influence of pre-traumatic and posttraumatic treatment with Ro5 4864, a peripheral-type (P-Site) benzodiazepine ligand. J Neuroimmunol 42(2):177-185

48. Touzani O, Boutin H, Chuquet J, Rothwell N (1999) Potential mechanisms of interleukin-1 involvement in cerebral ischaemia. J Neuroimmunol 100(1-2):203-215

49. Ungerstedt U (1991) Microdialysis - principles and applications for studies in animals and man. J Intern Med 230(4):365-373

50. Winter CD, Iannotti F, Pringle AK, Trikkas C, Clough GF, Church MK (2002) A microdialysis method for the recovery of IL-1 beta, IL-6 and nerve growth factor from human brain in vivo. J Neurosci Methods 119(1):45-50

51. Winter CD, Pringle AK, Clough GF, Church MK (2004) Raised parenchymal interleukin-6 levels correlate with improved outcome after traumatic brain injury. Brain 127:315-320

52. Woodroofe MN, Sarna GS, Wadhwa M, Hayes GM, Loughlin AJ, Tinker A, Cuzner ML (1991) Detection of interleukin-1 and interleukin-6 in adult-rat brain, following mechanical injury, by invivo microdialysis - evidence of a role for microglia in cytokine production. J Neuroimmunol 33(3):227-236

\section{Comments}

These are important validation studies, with the new $100 \mathrm{KD}$ microdialysis probes, in Vitro, and in vivo. They establish recovery rates of cytokines, the best perfusion rates and dialysate composition. Now it remains to be seen if Microdialysis using these new probes, can elucidate details of the pathobiology, of IL1 and IL6 in causes of brain damage, such as TBI, stroke, and SAH.

M. Ross Bullock

University of Miami Miller School of Medicine

I can only emphasise the importance of characterising the microdialysis technique to improve its potential applications in neurotrauma as in any other pathology. Since the extraction efficiency of cytokines in microdialysates is low, new strategies need to be established to maximise its retrieval. It would still remain to explain the lack of differences in cytokine concentration between TBI and sham animals.

Cristina Morganti-Kossmann Monash University 